\title{
UMA SANTA SAINDO DA PENUMBRA: ANÁLISE DAS NARRATIVAS DE PROFESSORAS DO ENSINO FUNDAMENTAL DA REDE PÚBLICA DE JUAZEIRO DO NORTE (CE) SOBRE A BEATA MARIA DE ARAÚJO
}

\author{
Renata Marinho Paz \\ Universidade Regional do Cariri (URCA), Juazeiro do Norte, Ceará, \\ Brasil \\ Ercília Maria Braga de Olinda \\ Universidade Federal do Ceará (UFC), Fortaleza, Ceará, Brasil
}

\begin{abstract}
Resumo: A proposta deste trabalho é analisar o lugar da beata Maria de Araújo nas narrativas de professoras do ensino fundamental da rede pública da cidade de Juazeiro do Norte (CE), considerando suas experiências religiosas e práticas pedagógicas relacionadas à disciplina Ensino Religioso. A partir do processo de biografização vivenciado no Círculo Reflexivo Biográfico, utilizando o método da compreensão cênica, foram realizadas análises das narrativas tecidas coletivamente pelas professoras, verificando-se a necessidade de avaliação crítica da disciplina Ensino Religioso, com o reconhecimento da importância histórica da beata Maria de Araújo e do lugar da religião na formação de Juazeiro, bem como a necessidade de problematização, no âmbito escolar, acerca dos processos de invisibilização feminina nos espaços públicos.
\end{abstract}

Palavras-chave: Ensino religioso. Beata Maria de Araújo. Narrativas. Círculo Reflexivo Biográfico.

Neste artigo apresentaremos reflexões acerca das narrativas sobre as práticas pedagógicas, bem como sobre as experiências religiosas de professoras da disciplina Ensino Religioso que atuam no Ensino Fundamental da rede pública, na cidade de Juazeiro do Norte (CE). Nossa proposta foi investigar o lugar da beata Maria de Araújo na história de Juazeiro, na vivência e na prática pedagógica dessas professoras, problematizando como as ideias por elas professadas repercutem em sua prática escolar, notadamente na disciplina Ensino Religioso.

Para realizar esta análise consideraremos algumas questões norteadoras: primeiramente, quem foi/é Maria de Araújo? Em que a disciplina Ensino Religioso pode contribuir para o conhecimento dessa personagem? Como o desconhecimento sobre a 
beata reverbera nas práticas pedagógicas das professoras dessa disciplina? Sendo o Estado laico, seria tarefa da escola abordar essas questões?

\section{A BEATA E OS EPISÓDIOS POR ELA PROTAGONIZADOS}

Maria Magdalena do Espírito Santo de Araújo nasceu no dia 24 de maio de 1862 em Taboleiro Grande, um pequeno distrito de Crato. Situado na Região do Cariri, sul da então Província do Ceará, o lugarejo futuramente se tornaria Juazeiro do Norte, conhecido espaço de romarias no Nordeste brasileiro. Descendente de negros e índios, Maria de Araújo, como era mais conhecida, levava uma vida humilde e piedosa, tendo se tornado, em 1885, uma das beatas do Padre Cícero.

Faz-se mister informar que os beatérios eram instituições difundidas no Brasil no período colonial. Conforme a historiadora Leila Algranti (1992), esses espaços eram destinados a mulheres que, por desejo ou por imposição social, levavam uma vida virtuosa e piedosa. Vinculados à igreja Católica Apostólica Romana, em geral eram semelhantes a conventos, mas não possuíam autorização canônica para seu funcionamento. Na região do Cariri existiam as Casas de Caridade, fundadas em meados do século XIX por Padre José Antônio Maria Ibiapina, e que seguiam o lema beneditino Ora et labora. As Caridades, como eram conhecidas, além de servir de beatérios, funcionavam como escolas para as filhas de fazendeiros e ricos comerciantes e, também, de orfanatos para crianças pobres (DELLA CAVA, 1976, p. 68). Nelas, as mulheres aprendiam a ler, a escrever e a contar, bem como a realizar trabalhos manuais que seriam aproveitados para o sustento da casa. As beatas eram consideradas modelos de virtude, sendo valorizadas pelas populações sertanejas. Durante o processo de romanização da igreja, Padre Ibiapina teve que abdicar da direção das Caridades.

Inspirado no modelo do Mestre Ibiapina, em 1885, após a realização de um retiro espiritual, Padre Cícero conferiu o manto de beatas a um grupo de mulheres que também fizeram votos de obediência, pobreza e castidade. Em sentido amplo, o termo beata pode ser empregado para mulheres que fizeram votos e que optaram por viver em instituições ou então em suas próprias casas.

Nossa personagem era órfã e sem estudos; trabalhava fazendo de tudo um pouco para sobreviver: lavava e engomava roupas, fazia serviços domésticos em casas de família, vendia bolos e doces, fiava, tecia, fazia pequenas costuras e bonecas para vender. Como as outras beatas, Maria de Araújo vivia sob votos de pobreza, obediência e castidade, e sua existência seguiria sem notoriedade até 1889. No dia 01 de março daquele ano, a beata havia passado a noite em vigília junto com outras mulheres do Apostolado da Oração em uma missa celebrada pelo Padre Cícero na capela de Nossa Senhora das Dores, pedindo a intercessão divina em face da seca que se avizinhava. Ao alvorecer, Padre Cícero ministrou a eucaristia aos presentes. Maria de Araújo, ao receber a comunhão, entrou em êxtase e não pôde deglutir a hóstia, pois a mesma se transformara em sangue.

Este fenômeno se repetiu por dois anos ${ }^{1}$, de acordo com depoimentos de centenas de pessoas de diferentes classes sociais, conforme divulgado na imprensa escrita da época, e foi rapidamente interpretado pelo povo e pelos clérigos da região 
PAZ, R. M.; OLINDA, E. M. B. de

como o sangue de Cristo sendo derramado em Juazeiro. De acordo com o historiador Régis Lopes Ramos (2000, p. 165):

Acreditava-se que Juazeiro era um espaço de comunicação entre a Terra e o Céu. A transformação da hóstia em sangue anunciava que o remoto povoado era um território de purificação e salvação da alma. O milagre significava um aviso de Deus para converter os desviados e alimentar a fé dos devotos.

As notícias a respeito desses fatos extraordinários, da santidade da beata e do Padre Cícero logo se alastraram pelos sertões, alcançando também repercussão na imprensa ${ }^{2}$, contribuindo para que Juazeiro se transformasse em espaço de romarias. Com a popularidade dos milagres ${ }^{3}$, pessoas das mais diversas localidades e condições sociais passaram a afluir a Juazeiro à procura de salvação para seus pecados e de oportunidades para se estabelecer.

Em 1891 a Diocese do Ceará constituiu uma Comissão Episcopal de Inquérito composta por dois padres da confiança do bispo Dom Joaquim José Vieira para averiguar os fatos que ocorriam em Juazeiro. Os sacerdotes, doutores em Teologia, após uma série de observações e análises, concluíram que não havia explicação natural para os acontecimentos, que foram considerados como milagrosos. Temendo as graves implicações teológicas de tal parecer, Dom Joaquim instituiu uma segunda Comissão Episcopal de Inquérito em 1892, que concluiu que os fatos não eram sobrenaturais e sim um embuste. Esses resultados foram enviados a Roma, que ratificou a posição da Comissão $0^{4}$. Enquanto isso, o fluxo de romeiros continuava a crescer e a santidade da beata e do Padre Cícero a se difundir.

Longe de ser um acontecimento isolado nos sertões nordestinos, a questão religiosa de Juazeiro traduzia o embate entre dois universos distintos que coabitavam e se confrontavam no interior da Igreja Católica. Os milagres de Juazeiro colocavam em xeque o projeto romanizador da igreja, que tinha por objetivo seu fortalecimento institucional através da centralidade da autoridade clerical. No século XIX a igreja se esforçava para consolidar a romanização no Brasil que, segundo Eduardo Hoornaert (1998), significava a europeização do catolicismo no país, que até então possuía feições fortemente devocionais e penitenciais, podendo ser caracterizado pelo ditado popular "muita reza, pouca missa, muito santo, pouco padre".

Os acontecimentos de Juazeiro deram início a um dos conflitos religiosos mais marcantes da Igreja Católica no Brasil, com um violento processo envolvendo o Padre Cícero e a beata Maria de Araújo, assim como outras beatas que conviviam com ela e o povo romeiro. Entre os anos de 1893 e 1897 quatro Cartas Pastorais foram publicadas pelo Bispo Dom Joaquim Vieira e, por meio delas, a igreja assumiu uma atitude contundente de controle e combate aos milagres e suas implicações teológicas, sobre a santificação do padre e da beata, bem como ao movimento romeiro. As romarias foram proibidas; não se podia falar sobre os milagres, e Padre Cícero foi suspenso de suas ordens sacerdotais, fato que persistiu por toda a sua vida. Alijado de suas ordens, acusado pelas elites civis e eclesiásticas de atuar como fanatizador e incentivador de crendices e de transformar Juazeiro numa "metrópole da superstição sertaneja" (DELLA CAVA, 1976, p. 113), restou ao patriarca de Juazeiro a função dos antigos conselheiros dos sertões. Em frente à sua casa, todos os dias aglomeravam-se centenas de romeiros para pedir conselhos, bênçãos 
e ajuda, a despeito dos esforços da igreja em debelar as romarias e a atração que ele exercia sobre os nordestinos.

As autoridades eclesiásticas também se voltaram contra Maria de Araújo. A beata, que era considerada pelo povo como um "[...] oráculo de inspiração divina com o poder de interceder junto a Deus" (DELLA CAVA, 1976, p. 79), passou a ser alvo de difamação, sendo considerada pela Igreja como histérica, fanática e embusteira. A ela foi imposto o isolamento, a fim de evitar o concurso de peregrinos, devotos e curiosos. Maria de Araújo foi julgada, difamada e condenada à reclusão, mas, mesmo assim, a exemplo do seu diretor espiritual, recusou-se até o fim de sua vida a denegar os milagres. A devoção inicial à beata foi sendo esquecida. Isolada, silenciada e detratada, a beata morreu no dia 17 de janeiro de 1914, sob o véu do esquecimento histórico. Por ordem do Padre Cícero, seu corpo foi sepultado no interior da capela do Socorro. Em 1930 seu túmulo foi violado a mando das autoridades eclesiásticas e seus restos mortais continuam desaparecidos até os dias de hoje.

Considerando as trajetórias das duas personagens centrais da trama aqui narrada, Olinda (2018, p. 105) levanta uma importante questão: "porque tanto o Padre Cícero quanto Maria de Araújo precisavam ser 'lançados ao chão'? O que eles ameaçavam?" Segundo a autora, é preciso ponderar sobre as diferentes variáveis que atuavam naquele contexto. Nas suas palavras:

Esta não é uma questão de fácil resposta. Com apoio da interseccionalidade, insisto em mostrar que variáveis diversas estavam implicadas nesta equação: o esfacelamento da igreja tradicional e o projeto de romanização; a posição política e social de um lugarejo perdido no Nordeste brasileiro; a posição da igreja sobre mulheres, laicato, negras e índias; a desqualificação das gentes simples, analfabetas ou pouco escolarizadas; o elitismo de uma sociedade que reservava aos pobres apenas um lugar subalterno, longe de considerações sobre dignidade e garantia de direitos.

Neste contexto, como admitir que um nordestino pobre pudesse ter recebido de Jesus Cristo a missão de cuidar dos oprimidos nordestinos? Como aceitar que uma mulher descendente de negras e de índias pudesse ser instrumento de Deus para a transformação da hóstia consagrada em sangue? [...] (OLINDA, 2018, p. 105-106).

A Igreja Católica conseguiu promover o apagamento de Maria de Araújo, mas não conseguiu dar cabo do concurso de romeiros a Juazeiro. Apesar da proibição de se falar sobre os milagres e do isolamento imposto à beata, os devotos continuavam a rememorar, difundir e alimentar a crença nos fatos extraordinários, ainda que, com o passar do tempo, de modo parcimonioso e indireto. Vale salientar também que a devoção ao Padre Cícero continuou e, junto com isso, o aumento na crença em sua capacidade de obrar milagres.

Paralelamente, Juazeiro também começou a se tornar um amplo filão editorial marcado muitas vezes por um tom faccioso. A produção literária elaborada ao longo de quase um século sobre o Padre Cícero, Juazeiro e as romarias possui diferentes abordagens, revelando diversas maneiras de apropriação, reelaboração e interpretação, 
segundo os momentos históricos e os interesses daqueles que ocupam o lugar e detêm o poder de escrever a História, o que certamente traz implicações na forma como esses elementos são percebidos para além dos textos. Seja defendendo ou atacando o Padre Cícero e os fatos de Juazeiro, um aspecto é evidente nessas narrativas: a constituição e a consolidação da centralidade e da santidade da figura do Padre Cícero. De um modo geral, nas histórias que vêm sendo escritas até recentemente sobre Juazeiro, não há lugar para a beata; nas poucas vezes em que Maria de Araújo é mencionada, quase sempre o é de forma subalterna, acessória e negativa, evidenciando a efetividade das medidas detratoras da Igreja Católica sobre ela. As palavras da pesquisadora Maria do Carmo Forti traduzem bem esta perspectiva:

Maria de Araújo faz parte daqueles 'sem-lugar', 'sem-poder', dos leigos, ou ainda mais, de acordo com o código de Direito Canônico vigente na época, abaixo dos leigos, pois era mulher. Ou ainda mais: abaixo do status de mulher, pois era negra: "raça infecta" pelas constituições do arcebispado da Bahia. E podemos ir mais longe na desqualificação de Maria de Araújo: era analfabeta. Ela, portanto, fazia parte daqueles que não constroem a história. (FORTI, 1999, p. 109).

Entretanto, parafraseando o historiador Pierre Nora (1993), a construção de narrativas históricas não é uma operação inocente. Esquecer isso é deixar de lado a percepção dos embates que são travados para a constituição de determinadas perspectivas em detrimento de outras. Neste sentido, o historiador Michel Pollak, ao refletir sobre os processos de silenciamento e apagamento das memórias, afirma que "[...] não se trata mais de lidar com os fatos sociais como coisas, mas de analisar como os fatos sociais se tornam coisas, como e por quem são solidificados e dotados de duração e estabilidade" (1989, p. 4).

A história oficial de Juazeiro, centrada no Padre Cícero, apaga a beata (as beatas, os beatos e o laicato de uma forma geral), mas também oculta outros universos de sentido religiosos. Não se trata, evidentemente, de negar a hegemonia do catolicismo em Juazeiro ${ }^{5}$, mas de vislumbrar o que vem sendo deixado de lado nesse processo. É preciso não esquecer também que a escrita da história sempre é inserida em contextos específicos.

Há cerca de três décadas ${ }^{6}$ vêm sendo feitos esforços para o alargamento da compreensão da história de Juazeiro e do Padre Cícero, tendo como base a perspectiva de que só seria possível conhecê-los de fato levando-se em consideração a presença e a atuação do povo, sobretudo da ação do laicato; assim, novos olhares começaram a ser construídos. As contribuições das análises realizadas com base no uso de fontes orais por diferentes campos do conhecimento (História, Antropologia, Sociologia etc.), ao privilegiar os excluídos, os marginalizados e as minorias, ressaltam a importância do que Pollak chama de "memórias subterrâneas" ou "clandestinas" (1989, p. 4-5). Ainda conforme esse autor, distinguir entre conjunturas favoráveis ou desfavoráveis às memórias marginalizadas é, de saída, reconhecer até que ponto o presente colore o passado; conforme as circunstâncias, ocorre a emergência de certas lembranças, a ênfase é dada a um ou outro aspecto (Idem, p. 6). 
Seguindo essa perspectiva, aos poucos o protagonismo de Maria de Araújo começou a vir à tona, assim como as disputas políticas e religiosas em torno dela. Entretanto, apesar dos esforços que vêm sendo realizados, sobretudo aqueles associados a pautas dos direitos humanos, capitaneados por diversos movimentos sociais e artísticos do Cariri, é notável a ausência de conhecimentos sobre a história e a atuação dessa mulher entre romeiros, devotos e moradores de Juazeiro, bem como entre alunos e professores, especialmente da disciplina Ensino Religioso ministrada no município de Juazeiro do Norte. A seguir, passaremos a essa questão.

\section{SILÊNCIOS E DESCONHECIMENTO A RESPEITO DE MARIA DE ARAÚJO}

Em 2017, a primeira autora deste artigo participou de um processo formativo dos professores da disciplina Ensino Religioso da rede pública de ensino fundamental de Juazeiro do Norte. Através de um questionário que foi respondido por 47 pessoas $^{7}$ foram abordados os seguintes aspectos: a) formação inicial e pós-graduada; b) importância da disciplina; c) compreensão sobre a natureza da disciplina, d) inserção do Padre Cícero e de Maria de Araújo na disciplina e os conteúdos que gostariam de ver contemplados nas formações continuadas ${ }^{8}$.

Sobre os dados coletados, um primeiro elemento que gostaríamos de destacar é a ausência de ações pedagógicas das escolas ou da universidade no que diz respeito à transmissão de conhecimentos sobre a beata Maria de Araújo. Em suas narrativas, as professoras mencionaram poucas referências em seus processos formativos a respeito do tema em tela. Embora em sua maioria católicas, as professoras demonstraram a necessidade de aprofundar seus conhecimentos sobre a beata, ora vista por elas como santa, ora como figura histórica a merecer respeito. Apesar de terem enfatizado a dimensão da transmissão intergeracional sobre valores religiosos (como será visto adiante), a maior parte das professoras não teve acesso a informações sobre Maria de Araújo, revelando a centralidade atribuída ao Padre Cícero no fenômeno religioso de Juazeiro. Além da formação incipiente, as professoras não contavam com material didático que tratasse sobre a beata. Apenas uma das professoras utilizava um conjunto de textos obtidos na internet com dados biográficos de Maria de Araújo e algumas referências a respeito do episódio do sangramento da hóstia. A professora já usava aquele material havia dois anos e explicou que, após a leitura dos textos, aplicava um questionário com perguntas literais sobre o que foi lido, sem qualquer problematização. Esse tipo de perspectiva reverbera na prática pedagógica dessas professoras. Como ensinar algo que não se conhece?

Para aprofundar a discussão sobre o modo como ao longo da vida foram se apropriando de conhecimentos sobre a beata e como a tratavam na prática pedagógica, foi realizado em 2018 um processo de biografização, vivenciado no Círculo Reflexivo Biográfico (CRB) ${ }^{9}$, envolvendo nove professoras da disciplina Ensino Religioso ${ }^{10}$. A seguir, apresentaremos a análise das narrativas tecidas coletivamente, utilizando a metodologia da compreensão cênica proposta por Marinas (2007).

Um primeiro aspecto a destacar nas narrativas é a construção da identidade como docente de Ensino Religioso. As professoras tinham graduação em História, 
Geografia e Pedagogia e afirmaram que jamais pensaram em ministrar a disciplina aqui focada. Quando chegaram à escola não receberam orientação e tiveram "que se virar". A superação das dificuldades iniciais na disciplina ainda está sendo vivenciada. Para a professora Luzia" ${ }^{11}$ sua adaptação só foi possível por três motivos: em primeiro lugar, a sua dedicação pessoal; em segundo, a busca de contato com a realidade de Juazeiro do Norte e por último, mas não menos importante, a sua fé, conforme expressa a seguir:

\begin{abstract}
Eu gosto do que faço. Adoro o convívio escolar e procuro estar sempre próximo dos meus alunos. Tento explicar meu conteúdo da maneira mais dinâmica e diversificada para um bom aprendizado, posteriormente. [...] Eu já acompanhei algumas romarias, com um grupo de amigos amadores da fotografia, há uns três anos, quando o meu tempo era mais livre. A gente fez um álbum belíssimo, com algumas fotos de uma romaria, mostrando a fé religiosa dessas pessoas que vêm anualmente, de tão longe, pagar suas promessas aos pés do Padre Cícero aqui em Juazeiro do Norte. Eu acredito em milagres. Quando uma pessoa realmente tem fé tudo pode acontecer mesmo. Acredito nos milagres do Padre Cícero ligado à beata Maria de Araújo, que ela, por algum motivo, foi a escolhida para vivenciar esse milagre.
\end{abstract}

É evidente o esforço individual em detrimento de políticas coletivas de formação, assim como o desejo da professora de desenvolver um vínculo com a disciplina que, por circunstâncias institucionais, coube-lhe lecionar, apesar de não possuir formação para tanto. Neste sentido, Marinilson Silva (2011), ao analisar a construção da identidade individual e coletiva do professor do Ensino Religioso, afirma que nas relações constituídas socioculturalmente e na mediação com outros (alteridade), o professor do Ensino Religioso vai ressignificando suas experiências no "[...] mundo de vida, onde são contempladas suas histórias de vida, as marcas de experiências de fé vividas no cotidiano, de busca de transcendência, de percepções e sentidos" (SILVA, 2011, p. 66).

As dificuldades em se sentir professora do Ensino Religioso estão ligadas não apenas à ausência de formação específica para tal, mas também aos seguintes motivos: a complexidade epistemológica e pedagógica da área, que ainda não conseguiu efetivar sua própria identidade no processo de escolarização; a abertura ao diálogo religioso das próprias professoras, que precisam ter clareza de sua opção religiosa, ou da ausência desta, assim como das suas concepções pedagógicas. Como lembra Junqueira (2005, p. 112), a formação do professor do Ensino Religioso não pode limitar-se "[...] ao estudo acadêmico dos conteúdos específicos. Após esta apropriação do 'discurso religioso' é preciso fazer a tradução pedagógica da linguagem religiosa, adaptando-a ao nível de desenvolvimento dos alunos em seus aspectos psicogenéticos e socioculturais".

Apesar de terem evitado tocar ou se alongar no tema da formação docente, houve consenso entre as professoras narradoras sobre a necessidade de reorientação, tanto na formação inicial na licenciatura quanto nas formações continuadas ofertadas pela Secretaria Municipal de Educação e nos cursos de especialização. No primeiro caso, foi considerado pela maioria que a temática da história local deve ser mais bem tratada, evitando-se superficialidades, fragmentações e intermitências. No segundo caso, todas acham que faltam, nas formações continuadas, os seguintes aspectos: conhecimento, por parte dos formadores, da realidade da escola pública de Juazeiro do Norte; valorização da 
experiência docente; ênfase nos aspectos metodológicos; e relação entre a teoria e a prática.

Diante de tantos relatos sobre as dificuldades de recursos materiais para as aulas na disciplina Ensino Religioso, fica a indagação de por que isso ocorre em uma região com tantas bibliotecas, memoriais, institutos de pesquisa e um acervo de Trabalhos de Conclusão de Cursos (TCC's), dissertações e teses versando sobre temas locais ${ }^{12}$. Muitos eventos vêm sendo realizados no Memorial Padre Cícero, na Universidade Regional do Cariri (URCA) e na Universidade Federal do Cariri (UFCA), tratando de questões pertinentes a aspectos culturais fundamentais sobre a região do Cariri, mas a participação dos professores da educação básica em geral é incipiente. Por que isso ocorre? Seria acomodação das professoras que não investem em sua formação? Seria falta de articulação entre Secretarias de Educação e entidades promotoras dos eventos? Seria a jornada exaustiva de trabalho a que são submetidas as professoras? Seria a falta de estímulo desde a formação inicial na licenciatura? Sem pretender alongar mais essa discussão, fica apenas a indicação da necessidade de que sejam criadas formas ágeis para que cheguem ao corpo docente das escolas públicas os resultados das pesquisas feitas sobre a região do Cariri, de modo que esse conhecimento seja transformado em conteúdo escolar acessível a todas as pessoas.

Um segundo aspecto a ser destacado refere-se à importância da disciplina. Todas consideraram que a mesma é fundamental para a formação básica de crianças e adolescentes, pois o acesso às elaborações sobre os conhecimentos produzidos pela humanidade no campo da religião é um direito de todas as pessoas. Havia grande inquietação entre as professoras sobre a inclusão ou não da disciplina Ensino Religioso na Base Nacional Comum Curricular (BNCC) e, caso fosse incluída, como terminou sendo, qual modelo seria contemplado: o confessional, o interconfessional ou o da(s) Ciência(s) da(s) Religião(ões)?

Na BNCC, o conhecimento religioso é o objeto da área de Ensino Religioso e este deve ser produzido nas Ciências Humanas e Sociais, notadamente no campo da(s) Ciência(s) da(s) Religião(ões), que investigam a manifestação dos fenômenos religiosos em suas múltiplas manifestações como "[...] parte integrante do substrato cultural da humanidade [...] em diferentes culturas e sociedades enquanto um dos bens simbólicos resultantes da busca humana por respostas aos enigmas do mundo, da vida e da morte" (BRASIL, 2018, p. 434).

O documento específico do Ensino Religioso já está sendo objeto de estudos pela equipe responsável por esta área no município de Juazeiro do Norte, com vistas à elaboração do currículo local. Esperamos que, no emaranhado de definições de competências e habilidades da BNCC, as dimensões praxiológica e inter-religiosa presentes nos Parâmetros Curriculares Nacionais, elaboradas em 1996 pelo Fórum Nacional Permanente do Ensino Religioso (FONAPER), sejam preservadas de modo a

[...] proporcionar o conhecimento dos elementos básicos que compõem o fenômeno religioso, a partir das experiências religiosas percebidas no contexto dos educandos, buscando disponibilizar esclarecimentos sobre o direito à diferença, valorizando a diversidade cultural religiosa presente na sociedade, no constante 
propósito de promoção dos direitos humanos (FONAPER, 2009, p. 3031).

Julgamos importante manter este espírito problematizador e pluralista, que parte dos fenômenos vividos e observados pelas estudantes como condição para fazer do Ensino Religioso um espaço concreto para a discussão sobre a importância, ou não, do conhecimento religioso para a vida de cada um e da sociedade.

Refletindo sobre os conteúdos sugeridos para futuras formações na disciplina Ensino Religioso, após a sugestão de uma multiplicidade de temas, as colaboradoras indicaram os cinco tópicos mais relevantes, que apresentamos a seguir: História das religiões; Respeito à diversidade religiosa; $O$ ser humano como um ser religioso; Religiosidade popular; Importância da religião na formação de Juazeiro do Norte e na vida das pessoas.

As elaborações das docentes demonstraram a reprodução da tendência de compreender o Ensino Religioso como espaço para ensino de valores e virtudes, desconectadas, às vezes, do próprio conhecimento religioso. À medida que as reflexões sobre a natureza da disciplina foram se aprofundando, as professoras começaram a ver a importância do conhecimento religioso, inclusive para a construção de uma cultura de paz e para a formação ética dos cidadãos. Vejamos algumas das respostas apresentadas:

O Ensino Religioso é uma das disciplinas de grande relevância no processo de desenvolvimento humano. O seu objetivo principal é proporcionar reflexões sobre os fundamentos, costumes e valores das várias religiões existentes na sociedade. O ensino religioso proporciona aos envolvidos uma formação integral, contribuindo, de forma direta, para um equilíbrio emocional, ajudando-os no cotidiano familiar e social (Joana).

É uma disciplina educacional que sugere pensamentos, costumes e valores das mais variadas religiões existentes, buscando a compreensão das mesmas (Adelaide).

O Ensino Religioso é uma disciplina descritiva e reflexiva, cujo objetivo é propor reflexões sobre fundamentos, valores e costumes das variadas religiões. Se caracteriza pela busca da compreensão de diferentes crenças existentes na sociedade, explorando temas de maneira interdisciplinar, de forma que estimulem o diálogo e o respeito entre as diversidades culturais e religiosas (Antônia).

Apenas uma professora colocou o estudo sobre a beata entre as prioridades, mas houve uma tomada de consciência sobre a discussão das questões religiosas envolvendo o Padre Cícero, a Diocese e o Vaticano no passado, assim como a contextualização da importância da religião na formação de Juazeiro do Norte e na vida cotidiana atual. Foi apresentada também uma grande preocupação com as violências na cidade, sobretudo a atingir os jovens negros e da periferia ${ }^{13}$.

As professoras querem entender a religião como busca de vínculos permanentes e profundos com Deus - religare - expressos numa dimensão fundamental do humano, sua condição de ser espiritual, sendo fator constitutivo do sujeito, tendo consequências, inclusive, nas outras esferas da vida. Como uma educação libertadora, precisa respeitar a experiência religiosa, daí porque é necessário compreender suas 
razões, seus sentimentos e sua fé; assim, o tema da diversidade religiosa ganha relevância. Nessa visão, o influxo da experiência religiosa aliada a uma prática cidadã de defesa de direitos e a vivências da afetividade e do amor, pode levar as pessoas a se melhorarem a cada dia. Nessa perspectiva, emerge o sentido de religião como "leitura do mundo" relere.

A tarefa de socializar o conhecimento religioso produzido pela humanidade ao longo de milênios é tarefa específica da disciplina escolar Ensino Religioso. No entanto, considerando que a religiosidade das pessoas e dos povos - ou sua ausência - é um tema fundamental na formação humana, deve ser tratada transversal e interdisciplinarmente na escola, envolvendo todos os educadores. Alguns indagarão: sendo o Estado laico, o que justificaria o Ensino Religioso nas escolas? Tal questão exige uma reflexão sobre o que se entende por laicidade e o que se compreende por Ensino Religioso. Começando por este último, é necessário reconhecer que a Lei de Diretrizes e Bases da Educação Nacional deu grande passo na superação do sentido de catequese e apontou para uma perspectiva inovadora, não confessional e amparada nas Ciências da(s) Religião(ões).

A laicidade não é uma categoria a-histórica. Sua concretização na França, país que levou às últimas consequências as discussões sobre esse princípio, foi amadurecendo ao longo de um século, com contribuições de iluministas e de positivistas (DOMINGOS, 2008). O princípio moderno da separação entre Estado e Igreja é uma conquista e não deve haver recuos nesse sentido. Entretanto, não se pode confundir laicidade com negação ou embaraçamento às religiões, passando por cima do direito à livre opção e vivência religiosa. A laicidade, como princípio democrático, precisa ser permanentemente problematizada, não estando dissociada da tolerância e do respeito às práticas religiosas. No Estado laico, há espaço para o Ensino Religioso não confessional, o que exige formação de professores nos Cursos de Licenciatura em Ciências da Religião. Manter o Ensino Religioso na escola sem formar professores é colaborar com a antiga e persistente perspectiva catequética e proselitista. Como ensinar o que não se sabe? Como buscar amparo nas Ciências da Religião sem ter tido acesso a tais conhecimentos?

A escola, como instituição social encravada na vida comunitária, sente o reflexo dos conflitos gerados pela intolerância religiosa no seu dia a dia. Cada vez mais são comuns formas de violências, veladas ou ostensivas, causadas por desavenças daqueles que não conseguem entender que vivemos em tempos plurais e que os indivíduos têm direito à livre opção religiosa, assim como têm o direito de expressá-la. Defendemos que grande parte das atitudes intolerantes decorre da ignorância em relação ao universo simbólico e doutrinário em que o outro se move. O mito secular de que "religião é assunto que não se discute" gerou o silenciamento e fortaleceu preconceitos, tirando a reflexão de espaços orientados pela razão e por um pensar sistematizado sobre o fenômeno religioso, gerador do conhecimento religioso. Cabe também à escola, por ser encarregada de garantir o acesso ao conhecimento acumulado pela humanidade, discutir o conhecimento religioso, que também é conhecimento humano.

Compreendendo o fenômeno religioso, a escola poderá atuar adequadamente, respeitando direitos e promovendo uma perspectiva de diálogo. Para tanto, há que se fortalecer uma perspectiva emancipatória em educação, entendendo a escola como 
comunidade de aprendizagens que lida com o saber acumulado pela humanidade. Saber não apenas científico, mas também filosófico, artístico, do senso comum e religioso.

Um último aspecto que gostaríamos de destacar nas narrativas dessas professoras é a dimensão da transmissão transgeracional. Um traço comum é a força exercida pelos ensinamentos repassados, sobretudo pelas mulheres de suas famílias: mães, avós e tias predominam no exercício do papel de formadoras religiosas domésticas. Seus ensinamentos não se restringiram à transmissão oral, mas se desdobraram também em práticas devocionais vividas cotidianamente no lar e na frequência à igreja. As práticas rituais, como as renovações ao Sagrado Coração de Jesus ${ }^{14}$, a missa nos dias de domingo, o pagamento de promessas, o vestir-se de preto a cada dia $20^{15}$ e o culto doméstico com orações fizeram parte da experiência de formação religiosa das narradoras. Todas se referem a essas práticas e ritos que simbolizam a santidade do Padre Cícero e a atualização dos acontecimentos mais significativos em torno da construção de Juazeiro como cidade sagrada. Ao transmitirem relatos sobre as qualidades do padim Ciço, seja como curador, conselheiro ou intercessor junto a Jesus, essas mulheres atualizam o mito e perpetuam o santo, aproximando-o de si.

Se por um lado as professoras-narradoras enfatizam a recepção e transmissão dessas crenças e práticas ao longo de suas trajetórias de vida familiar, por outro, os estudantes da Escola de Ensino Fundamental Sebastião Teixeira, situada na colina do Horto - local onde está a estátua do padre Cícero entre outros equipamentos religiosos , já não escutam dos pais as histórias sobre o Juazeiro, pois a fonte principal de informações para seus questionamentos vem das redes sociais. Em uma roda de conversa realizada com estudantes da Escola Sebastião Teixeira, os jovens disseram que além de não ouvirem sobre essas histórias em casa, também não conversam com os romeiros; quando são dispensados da escola em época de romaria, ou vão ajudar os pais no comércio ambulante ou ficam em casa "zapeando e/ou tuitando".

Diante disso, é possível entrever um processo de ruptura cultural em curso entre as gerações, associado ao que a socióloga francesa Danièle Hervieu-Léger (2008) denomina de crise de transmissão. Ao discutir a desconstrução dos sistemas tradicionais de crença e as características da mobilidade no campo religioso contemporâneo, a autora não nega a persistência da transmissão das identidades religiosas de uma geração à outra, mas pontua uma crise significativa nessa transmissão, crise que precisa ser compreendida por pais, educadores, religiosos e pesquisadores, pois "[...] a transmissão regular das instituições e dos valores de uma geração a outra é, para toda sociedade, a condição de sua sobrevivência no tempo" (HERVIEU-LÉGER, 2008, p. 56). Essa crise de transmissão, associada às dificuldades nos processos formativos das professoras responsáveis pela disciplina Ensino Religioso, aponta para a urgência de enfrentamento desse quadro.

\section{CONSIDERAÇÕES FINAIS}

Independentemente da filiação religiosa precisamos reconhecer a importância histórica tanto do Pe. Cícero quanto da beata Maria de Araújo para a cidade de Juazeiro do Norte, assim como para os demais estados nordestinos. Se as novas gerações já não têm contato através de suas vivências familiares com as histórias de Juazeiro, do Padre Cícero e da beata, é preciso avaliar criticamente o lugar da disciplina Ensino Religioso neste processo de transmissão e produção de conhecimentos, considerando aqui 
especialmente aqueles relacionados à beata Maria de Araújo e aos meandros do processo de seu apagamento. Essa questão anuncia a importância de discutir sobre essas personagens, denotando o lugar da religião na formação de Juazeiro do Norte e na vida das pessoas, podendo contribuir também para a problematização, no âmbito escolar, acerca dos processos de invisibilização feminina nos espaços públicos.

Além disso, o Cariri e Juazeiro do Norte não podem mais continuar sendo apresentados apenas como espaço fértil das romarias e do catolicismo, mas como um espaço pulsante e contraditório, onde a tradição se comunica com um mundo tecnologizado e permeado de tensões e medos. O mundo real, habitado pelas crianças e adolescentes que estão nas escolas públicas, traz uma infinidade de conflitos e negações de direitos, fruto das desigualdades sociais. Planejar as atividades escolares a partir dos conhecimentos, das inquietações e das experiências socioculturais dos educandos, conforme orientações do educador Paulo Freire, é mergulhar nesse mundo real para tentar compreendê-lo e modificá-lo, contribuindo para fornecer elementos para a compreensão crítica da comunidade na qual docentes e estudantes vivem.

É ir na contramão do obscurantismo da noção de "escola sem partido" para encontrar o tom não confessional na discussão sobre o fenômeno religioso, e suas consequências para a formação humana.

Artigo recebido em: 30/01/2019 Aprovado para publicação em: 17/04/2019

\title{
A SAINT GOING OUT OF THE SHADOW: ANALYSIS OF NARRATIVES OF PRIMARY PUBLIC EDUCATION TEACHERS OF JUAZEIRO DO NORTE (CE) ABOUT BEATA MARIA DE ARAÚJO
}

\begin{abstract}
The purpose of this work is to analyze the place of Beata Maria de Araújo in the narratives of primary school teachers in the city of Juazeiro do Norte (CE), considering their religious experiences and pedagogical practices related to the discipline of Religious Education. From the biographical process experienced in the Biographical Reflective Circle, using the method of scenic comprehension, analyzes of the narratives produced collectively by the teachers were verified, verifying the need for a critical evaluation of the Religious Teaching discipline, with the recognition of the historical importance of the Beata Maria de Araújo and the place of religion in the formation of Juazeiro, as well as the need to problematize, in the school context, about the processes of female invisibilization in public spaces.
\end{abstract}

KEYWORDS: Religious Education. Beata Maria de Araújo. Narratives. Biographical Reflective Circle.

UMA SANTA SALIENDO DE LA PENUMBRA: ANÁLISIS DE NARRATIVAS DE PROFESSORAS DE LA ENSEÑANZA FUNDAMENTAL DE LA RED PÚBLICA DE JUAZEIRO DO NORTE (CE) SOBRE LA BEATA MARIA DE ARAÚJO 
RESUMEN: La propuesta de este trabajo es analizar el lugar de la Beata María de Araújo en las narrativas de profesoras de la enseñanza fundamental de la red pública de la ciudad de Juazeiro do Norte (CE), considerando sus experiencias religiosas y prácticas pedagógicas relacionadas a la disciplina Educación Religiosa. A partir del proceso de biografización vivido en el Círculo Reflexivo Biográfico, utilizando el método de la comprensión escénica, se realizaron análisis de las narrativas tejidas colectivamente por las profesoras, verificándose la necesidad de evaluación crítica de la disciplina Educación Religiosa, con el reconocimiento de la importancia histórica de la Beata y del lugar de la religión en la formación de Juazeiro, así como la necesidad de problematización, en el ámbito escolar, acerca de los procesos de invisibilización femenina en los espacios públicos.

PALABRAS CLAVE: Educación religiosa. narrativas. Beata Maria de Araújo. Circulo Reflexivo Biografico.

\section{NOTAS}

1) De acordo com Forti (1999, p. 94), a hóstia sangrou "[...] pelo menos 92 vezes documentadas". Na sua participação em mesa redonda no Seminário Maria Madalena do Espírito Santo Araújo: Onde ela Está?, realizado nos dias 22 e 23 de maio de 2018 na Universidade Regional do Cariri (URCA), Renato Dantas, historiador local e profundo conhecedor do tema em tela informou que, nas suas pesquisas, registrou 120 vezes a transformação da hóstia em sangue ou em carne.

2) Segundo Pinho (2015), na época dos acontecimentos, sessenta jornais brasileiros, um francês e um inglês fizeram referências aos milagres, à beata Maria de Araújo, ao padre Cícero e à presença de romeiros em Juazeiro através de cartas, testemunhos, artigos e editoriais. Com isso, o pequeno vilarejo passou a sobressair na imprensa, e os fatos passaram a ter uma publicidade não esperada e nem desejada pela Igreja Católica.

3) Assumimos o termo milagre, sem utilizar aspas, mas não temos a pretensão de entrar no mérito da teologia dogmática para discutir o significado canônico do termo. Assumimos a "verdade" do termo em respeito à conotação atribuída pelos populares ao fenômeno, cuja intenção é designar algo extraordinário, onde a "mão de Deus" estaria presente, tratando-se, portanto, de uma afirmação de fé.

4) A íntegra dos dois documentos dos inquéritos pode ser consultada na Cúria Diocesana do Crato, que também foram socializados por Guimarães e Dumoulin (2003).

5) Segundo os dados do censo 2010 realizado pelo IBGE, Juazeiro do Norte possui pouco mais de $87 \%$ de pessoas que se declaram católicas (ver https://cidades.ibge.gov.br/brasil/ce/juazeiro-donorte/panorama. Acesso em 03 de janeiro de 2019).

6) Um dos marcos deste processo foi a realização dos Simpósios Internacionais sobre o padre Cícero, a partir de 1988, em Juazeiro do Norte. Destacamos especialmente o II Simpósio, realizado em 1989, cuja temática versou sobre a beata Maria de Araújo e o milagre. Para o conhecimento sobre o modo como a beata em foco foi tratada nos referidos Simpósios ver Olinda e Cordeiro (2018).

7) Estavam presentes 64 docentes, destas, 14 responderam ao questionário sobre os Estudos Regionais, 33 responderam ao questionário de Ensino Religioso e 17 preferiram não responder. 8) Enfocaremos apenas os conteúdos referentes à disciplina Ensino Religioso.

9) O Círculo Reflexivo Biográfico é um dispositivo (procedimento, mecanismo) de pesquisa e de formação desenvolvido de forma coletiva e cooperativa no Grupo de Pesquisa Dialogicidade Formação Humana e Narrativas, visando a garantir um processo de biografização nas seguintes modalidades: narrativas de vida; narrativas de formação; e narrativas da experiência religiosa. Em 
cada uma das modalidades são produzidos textos escritos denominados, respectivamente, da seguinte forma: história de vida; biografia educativa (DOMINICĖ, 1988); e narrativa da experiência religiosa.

10) As professoras foram selecionadas a partir dos seguintes critérios: pertencer ao quadro permanente de professores da rede pública municipal de Juazeiro do Norte e ministrar a disciplina Ensino Religioso há, pelo menos, dois anos. A análise completa das narrativas pode ser encontrada em Olinda (2008).

11) Estamos utilizando nomes fictícios.

12) No espaço do V Simpósio Internacional sobre o Padre Cícero (março de 2017), criamos o Programa de Extensão Laboratório Transdisciplinar das Religiões no Cariri, envolvendo a UFC, UFCA e URCA. Um dos objetivos é exatamente organizar uma base de trabalhos acadêmicos com a temática da religiosidade para disponibilizar ao público em geral.

13) Resultados da pesquisa "Cada vida importa: evidências e recomendações para a prevenção de homicídios na adolescência" (CEARÁ, 2016), realizada em sete municípios cearenses, entre eles Juazeiro do Norte, revelam que o estado ocupa o terceiro lugar no Brasil no número de mortes entre jovens de 12 a 18 anos de idade. Dos adolescentes assassinados, 97,95\% eram do sexo masculino, $69,75 \%$ eram negros ou pardos e mais de $70 \%$ desses jovens estavam fora da escola há, pelo menos, seis meses. Muito cedo, esses jovens são apresentados às drogas e às armas de fogo. Vivem em bairros com pouca ou nenhuma infraestrutura física e de serviços. Existe uma permanente relação conflituosa entre polícia e comunidade, com intimidações e violências, especialmente contra jovens. Todos esses fatores reunidos caracterizam uma acentuada segregação urbana, que contribui para a vulnerabilidade à violência letal.

14) Prática devocional doméstica conduzida por leigos e difundida pelo padre Cícero. Toda a família e membros da comunidade renovam os votos de fé no Sagrado Coração de Jesus anualmente em data fixa.

15) Prática difundida pelos romeiros para lembrar a data do falecimento do Pe. Cícero, ocorrida em 20 de julho de 1934 e rememorada todos os meses.

\section{REFERÊNCIAS}

ALGRANTI, Leila Mezan. Honradas e devotas: Mulheres da colônia. Brasília: EdUNB, 1992.

BRASIL. Base Nacional Comum Curricular. Brasília: MEC. Disponível em http://basenacionalcomum.mec.gov.br/wpcontent/uploads/2018/06/BNCC_EI_EF_1105 18_versaofinal_site.pdf. Acesso em: 20 ago. 2018.

CEARÁ. Cada vida importa: evidências e recomendações para a prevenção de homicídios na adolescência. Fortaleza: CCPHA, 2016. Disponível em https://www.al.ce.gov.br/phocadownload/relatorio_final.pdf. Acesso em: 03 ago. 2018.

DELLA CAVA, Ralph. Milagre em Joaseiro. São Paulo: Paz e Terra, 1976.

DOMINICÉ, P. A biografia educativa: instrumento de investigação para a educação de adultos. In: NÓVOA, A.; FINGER, M. O método (auto)biográfico e a formação. Lisboa: MS/DRHS/CFAP, 1988 
PAZ, R. M.; OLINDA, E. M. B. de

DOMINGOS, Marília de F. N. Escola e laicidade: o modelo francês. In: Revista Cultura e Comunidade. V.3, N.4. 2008, p. 153-170.

FONAPER - Fórum Nacional Permanente do Ensino Religioso. Parâmetros Curriculares Nacionais do Ensino Religioso. São Paulo: Mundo Mirim, 2009.

FORTI, Maria do Carmo Pagan. Maria do Juazeiro: a Beata do Milagre. São Paulo: Annablume, 1999.

GUIMARÃES, Therezinha Stella; DUMOULIN, Annette. Leitura comparativa das digitações do processo instruído sobre os fatos de Juazeiro- Versão "Maria do Carmo" - "Versão Salatiel". Juazeiro do Norte: Instituto de Psicologia da Religião, 2003.

JUNQUEIRA, S. A.; OLIVEIRA, Lilian Blanck (Org.). Ensino religioso: memória e perspectivas. Curitiba: Champagnat, 2005.

HERVIEU-LÉGER, Danièle. O peregrino e o convertido. A religião em movimento. Petrópolis: Vozes, 2008.

HOORNAERT, Eduardo. História da Igreja na América Latina e no Brasil. Rio de Janeiro: Bertrand Brasil, 1998.

NORA, Pierre. "Entre memória e história. A problemática dos lugares". (Trad. Yara Kaun Khoury). In Proj. História, São Paulo (10), dez. 1993.

OLINDA, Erćilia Maria Braga de.Uma santa na penumbra: razões entrecruzadas para o isolamento da beata Maria de Araújo na história e na prática pedagógica do ensino fundamental. Fortaleza. Tese para progressão ao cargo de professora titular, 2018.

OLINDA, Ercília Maria Braga de; CORDEIRO, Maria Paula. A beata Maria de Araújo nos simpósios internacionais sobre o padre Cícero: traços de uma protagonista invisibilizada. In: Revista Reflexão: PUC-Campinas, 2018 (No prelo).

PINHO, Maria de Fátima Morais. "Acontecimentos extraordinários do Joaseiro: o milagre da transformação da Hóstia Sagrada, em sangue, nas páginas do jornal O apóstolo, do Rio de Janeiro (1889 - 1898). In Anais do XXVIII Simpósio Nacional de História. Lugares dos historiadores: velhos e novos desafios. Florianópolis, 2015.

POLLAK, Michel. "Memória, esquecimento, silêncio". Estudos Históricos, Rio de Janeiro, vol. 2, n. 3, 1989, p. 3-15.

RAMOS, Francisco Régis Lopes. O meio do mundo: territórios do sagrado em Juazeiro do Padre Cícero. Tese de doutoramento em História, 2000.

SILVA, Marinilson B. de. Em busca do significado de ser professor do Ensino Religioso. João Pessoa-PB: Editora da UFPB, 2011. 
Renata Marinho Paz: Professora Associada do Departamento de Ciências Sociais da Universidade Regional do Cariri (URCA). Possui doutorado em Sociologia pela Universidade Federal do Ceará. Linhas de Pesquisa: Religião, Cultura popular e Patrimônio Imaterial. Tem interesse em abordagens qualitativas baseadas na etnografia e na pesquisa (auto) biográfica.

Orcid: https://orcid.org/0000-0002-5957-5023

E-mail: rmarinhopaz@gmail.com

Ercília Maria Braga de Olinda: Professora Titular do Departamento de Educação da Universidade Federal do Ceará (UFC). Possui doutorado em Educação pela UFC. Linhas de pesquisa: Educação Popular, Educação em Direitos Humanos, Juventude, Espiritualidade, Religião e Formação de professores. É líder do grupo de pesquisa Dialogicidade, Formação Humana e Narrativas, onde realiza investigações qualitativas baseadas na pesquisa (auto) biográfica, pesquisa-ação e etnografia.

Orcid: https://orcid.org/0000-0001-6442-3596

E-mail: bragadeolinda@yahoo.com.br

Este periódico utiliza a licença Creative Commons Attribution 3.0, para periódicos de acesso aberto (Open Archives Iniciative - OAI). 